\title{
Postjunctional electrical mechanisms of enteric neurotransmission
}

\author{
K M Sanders
}

The contractile behaviour of gastrointestinal smooth muscles is dependent on the intrinsic electrical activities of the muscles. ${ }^{1}$ Depolarisation activates $\mathrm{L}$-type $\mathrm{Ca}^{2+}$ channels that provide the main pathway for $\mathrm{Ca}^{2+}$ to enter gastrointestinal smooth muscle cells. This is particularly true for the phasic portions of the gastrointestinal tract where cyclic depolarisations and repolarisations, referred to as slow waves, set the contractile frequency and maintain the phasic nature of contractions (fig 1). The slow wave cycle ensures a period of relaxation between contractions, allowing mixing and movement of luminal contents. Tonic regions of the gastrointestinal tract, such as the sphincters, are also regulated by electrical events but primarily by more persistent changes in resting membrane potential.

In addition to the ionic conductances that contribute to resting membrane potential and electrical rhythmicity, there are several ionic conductances that are modulated by neural and hormonal inputs. Regulatory inputs from nerves, hormones, and paracrine substances are superimposed on the spontaneous electrical activity of gastrointestinal muscles. Electrical responses to biologically active substances result from: (i) modulation of ionic conductances that are already active and going through dynamic changes in open probability during the slow wave cycle; and (ii) activation of agonist dependent conductances that do not participate in basal electrical activity. $\mathrm{Ca}^{2+}$ entry into smooth muscles is mainly controlled by rather subtle changes in the open probability of L-type $\mathrm{Ca}^{2+}$ channels. ${ }^{23}$ The more frequently these channels open and the longer they stay open, the more major their influence on cytoplasmic $\mathrm{Ca}^{2+}$. Studies of ion channel regulation in gastrointestinal muscles have led to the general hypothesis that regulation of $\mathrm{Ca}^{2+}$ entry in gastrointestinal muscles is primarily accomplished by regulation of conductances other than L-type $\mathrm{Ca}^{2+}$ channels. In general, excitatory transmitters and hormones increase $\mathrm{Na}^{+}$influx through non-selective cation channels (fig 2). The resulting depolarisation and elevation in slow wave amplitude increases the open probability of $\mathrm{Ca}^{2+}$ channels. Inhibitory transmitters enhance the open probabilities of a variety of $\mathrm{K}^{+}$channels (fig 3 ). Hyperpolarisation and reduced excitability decreases $\mathrm{Ca}^{2+}$ channel open probability. In excitatory and inhibitory neurotransmission, membrane potential appears to be the main factor regulating the open probability of L-type $\mathrm{Ca}^{2+}$ channels.

Stimulation of muscarinic receptors causes activation of non-selective cation channels in gastrointestinal muscles. This conductance has been observed and characterised in several species, and several generalisations are possible. Little or none of the non-selective cation current is available in unstimulated gastrointestinal muscles. The conductance is activated by receptor occupation and a pertussis toxin sensitive $G$ protein, suggesting coupling through $\mathrm{G}_{\mathrm{i}} / \mathrm{G}_{\mathrm{o}}{ }^{4}$ The conductance is facilitated by intracellular $\mathrm{Ca}^{2+}$. The single channel conductance appears to be $20-30 \mathrm{pS}$, and the channels are voltage dependent over the physiological range of potentials. A number of ions and drugs block this conductance (for example, $\mathrm{Gd}^{3+}, \mathrm{Cd}^{2+}, \mathrm{Ni}^{2+}$, quinine, and fenamates)

Abbreviations used in this paper: ICC, interstitial cells of Cajal; cAMP, cyclic adenosine monophosphate.

Smooth muscle cells respond

to slow wave depolarisations with increased

$\mathrm{Ca}^{2+}$ channel open probability
Department of Physiology and Cell Biology, University of Nevada School of Medicine, Manville Medical Sciences Building, Reno, Nevada 89557, USA

KM Sanders

Correspondence to: Dr K M Sanders.

kent@physio.unr.edu

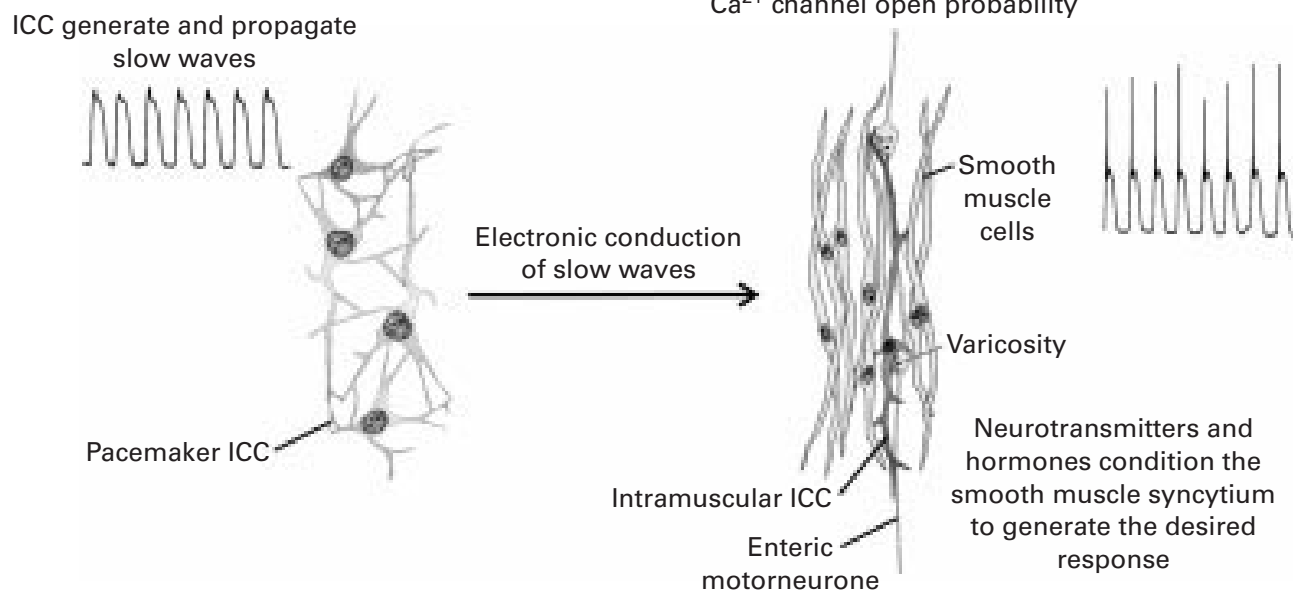

Figure 1 Organisation of electrical activity in phasic gastrointestinal muscles. ICC, interstitial cells of Cajal. 


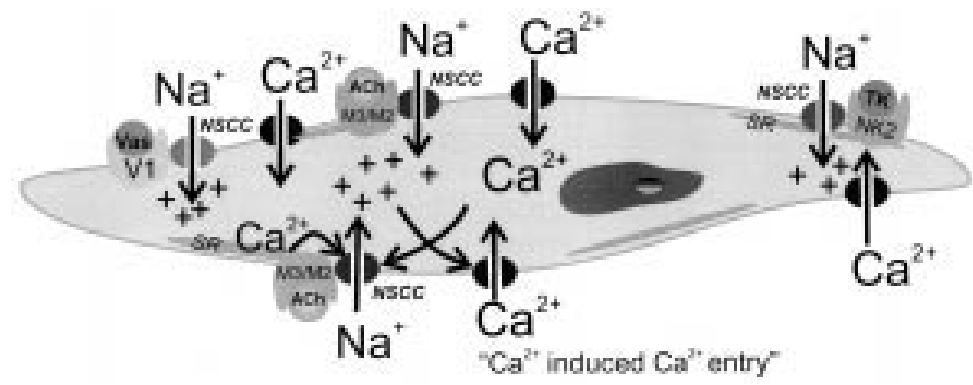

Currents via non-selective cation channels depolarise muscle cells and increase open probability of L-type $\mathrm{Ca}^{2+}$ channels

Figure 2 Acetylcholine (ACh), tachykinins (TK), and excitatory hormones activate non-selective cation channels. NSCC, non-selective cation current; Vas, vasopressin; SR, sarcoplasmic reticulum; NK2, neurokinin 2.

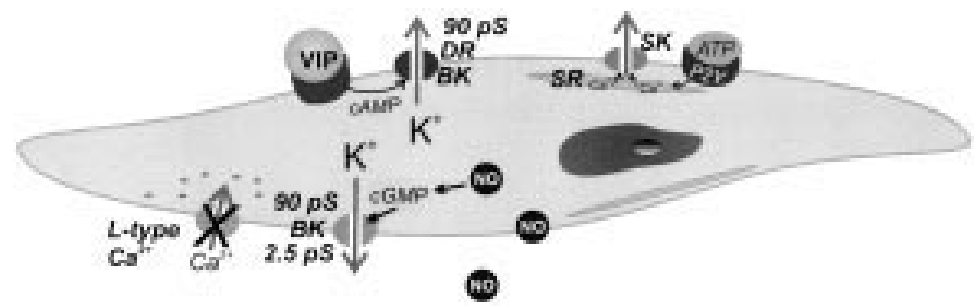

Activation of potassium channels reduces open probability of calcium channels and reduces contractions

Figure 3 Inhibitory agonists activate potassium channels in gastrointestinal smooth muscles. VIP, vasoactive intestinal peptide; cAMP, cyclic adenosine monophosphate; GMP cyclic guanosine monophosphate; $S K$, small conductance $\mathrm{Ca}^{2+}$ activated $\mathrm{K}^{+}$channel; $S R$, sarcoplasmic reticulum; $P 2 Y$, purinergic receptor type $P 2 Y ; D R$, delayed rectifier; BK, large conductance $\mathrm{Ca}^{2+}$ activated $\mathrm{K}^{+}$channel.

but specific blockers have not been identified. Although the non-selective channels are permeable to $\mathrm{Ca}^{2+}$, they conduct very little $\mathrm{Ca}^{2+}$ in physiological ionic gradients. Stimulation of tachykinin receptors also activates a nonselective cation conductance. However, the channels responsible appear to be distinct from those activated by muscarinic stimulation, as the tachykinin induced current is not facilitated by $\mathrm{Ca}^{2+}$ and currents activated by the two agonists summate. ${ }^{5}$ The non-selective cation conductances are nearly equally permeable to $\mathrm{Na}^{+}$and $\mathrm{K}^{+}$and the current produced by the conductance reverses at approximately $0 \mathrm{mV}$. As gastrointestinal muscle cells operate at potentials negative to $0 \mathrm{mV}$, the net current through non-selective cation channels is always inward and carried predominantly by $\mathrm{Na}^{+}$ions. Entry of $\mathrm{Na}^{+}$has no known effect on the contractile process, but the depolarisation caused by entry of positive charge increases the open probability of $\mathrm{Ca}^{2+}$ channels.

A variety of inhibitory transmitters and hormones elicit responses via enhanced production of cyclic adenosine monophosphate (cAMP). These include noradrenaline, vasoactive intestinal peptide, pituitary activating cyclic AMP peptide $\mathrm{P}$, adenosine (P1 receptors), and secretin. cAMP produces paradoxical effects on L-type $\mathrm{Ca}^{2+}$ currents, in that cAMP dependent mechanisms enhance $\mathrm{Ca}^{2+}$ current in smooth muscle myocytes. ${ }^{6}$ This effect is likely to be due to phosphorylation by cAMP dependent protein kinase $\mathrm{A}$, which is known to increase $\mathrm{Ca}^{2+}$ current in heart and other tissues. ${ }^{7}$ This trend, which would tend to make agonists that use cAMP dependent pathways excitatory, is counteracted in gastrointestinal muscles by concomitant activation of a variety of $\mathrm{K}^{+}$channels. Activation of $\mathrm{K}^{+}$channels limits excitability and decreases the open probability of $\mathrm{Ca}^{2+}$ channels. The types of $\mathrm{K}^{+}$ channels expressed and utilised in cAMP dependent responses vary in different species and in different parts of the gastrointestinal tract. We know at least that ATP dependent $\mathrm{K}^{+}$ channels, ${ }^{8}$ large conductance (BK) $\mathrm{Ca}^{2+}$ activated $\mathrm{K}^{+}$channels, ${ }^{9} 15 \mathrm{pS}$ delayed rectifier $\mathrm{K}^{+}$ channels, and $90 \mathrm{pS}$ voltage dependent $\mathrm{K}^{+10}$ can be activated in gastrointestinal muscle cells by cAMP dependent mechanisms. Other channels, such as an inward rectifier $\mathrm{K}^{+}$channel, may also be regulated by cAMP dependent mechanisms and contribute to the changes in resting potential noted in response to agonists that enhance cAMP. Nitric oxide and cyclic guanosine monophosphate dependent mechanisms are also coupled to activation of several types of $\mathrm{K}^{+}$channels, some of which are discrete from the channels activated by cAMP. ${ }^{11}$

Electrical mechanisms are supplemented and further regulated by release and uptake of $\mathrm{Ca}^{2+}$ from stores. Release of $\mathrm{Ca}^{2+}$ from stores can sum with $\mathrm{Ca}^{2+}$ entry to increase cytoplasmic levels but a more subtle form of regulation has also been described. Many of the conductances involved in electrical rhythmicity and agonist responses are sensitive to intracellular $\mathrm{Ca}^{2+}, 9$ so localised changes in $\mathrm{Ca}^{2+}$ near the membrane can significantly influence open probability. Recent studies have demonstrated that fundamental $\mathrm{Ca}^{2+}$ release events from stores $\left(\mathrm{Ca}^{2+}\right.$ sparks $)$ regulate the open probabilities of $\mathrm{Ca}^{2+}$ dependent channels. ${ }^{12}$ Small conductance $\mathrm{Ca}^{2+}$ activated $\mathrm{K}^{+}$channels have been found to mediate responses to ATP, another enteric inhibitory neurotransmitter, and these channels may be regulated primarily by $\mathrm{Ca}^{2+}$ release from stores. ${ }^{13}{ }^{14}$ Modulating uptake and release of $\mathrm{Ca}^{2+}$ offers an important regulatory control on spark activity and the open probabilities of $\mathrm{Ca}^{2+}$ dependent channels.

There is growing evidence that neural inputs to the muscular components of the gastrointestinal tract are mediated, in part, via interstitial cells of Cajal (ICC). ${ }^{15}$ It will be important in future studies to compare the relative responsiveness of ICC and smooth muscle cells. It is anticipated that specific receptors, second messengers, and/or ion channels may be expressed to a greater extent by ICC. It is also possible that the mechanisms for transducing signals from neurotransmitters are equally expressed by smooth muscle cells and ICC, but the close proximity of ICC to varicose nerve terminals causes these cells to experience much higher concentrations of neurotransmitter substances. Studies to delineate these questions await identification of the classes of ICC thought to mediate neurotransmission and comparative studies between ICC and smooth muscle cells. 
1 Szurszewski JH. Electrical basis for gastrointestinal motility. In: Johnson LR, ed. Physiology of the gastrointestinal tract.

2 Vogalis F, Publicover NG, Hume JR, et al. Relationship between calcium current and cytosolic calcium concentration in canine gastric smooth muscle cells. Am F Physio 1991;260:C1012-18

3 Fleischmann BK, Murray RK, Kotlikoff MI. Voltage window for sustained elevation of cytosolic calcium in smooth muscle cells. Proc Natl Acad Sci USA 1994;91 11914-18.

4 Inoue $\mathrm{R}$, Isenberg G. Acetylcholine activates nonselective cation channels in guinea pig ileum through a $\mathrm{G}$ protein. Am f Physiol 1990;258:C1173-8.

5 Lee HK, Shuttleworth CW, Sanders KM. Tachykinins activate non-selective currents in canine colonic myocytes. $A m$ fPhysiol 1995;269:C1394-401.

$6 \mathrm{Koh}$ SD, Sanders KM. Modulation of $\mathrm{Ca}^{2+}$ current in canine colonic myocytes by cyclic nucleotide-dependent canine colonic myocytes by cyclic nucleotide-dep
mechanisms. Am $\mathcal{F}$ Physiol 1996;271:C794-803.

7 Trautwein W, Hescheler J. Regulation of cardiac L-type calcium current by phosphorylation and G proteins. Ann Rev cium current by phosph

8 Zhang L, Bonev AD, Mawe GM, et al. Protein kinase A mediates activation of ATP-sensitive $\mathrm{K}^{+}$currents by CGRP in gallbladder smooth muscle. Am f Physiol 1994;267: G494-9.

9 Carl A, Lee HK, Sanders KM. Regulation of ion channels in smooth muscles by calcium. Am f Physiol 1996;271:C9-34.

10 Koh SD, Sanders KM, Carl A. Regulation of smooth muscle delayed rectifier $\mathrm{K}^{+}$channels by protein kinase $\mathrm{A}$. Pflügers Arch 1996;432:401-12.

11 Koh SD, Campbell JD, Carl A, et al. Nitric oxide activates multiple potassium channels in canine colonic smooth muscle. F Physiol 1995;489:735-43.

12 Nelson MT, Cheng H, Rubart M, et al. Relaxation of arterial smooth muscle by calcium sparks. Science 1995;270:633-7.

13 Koh SD, Dick GM, Sanders KM. Small conductance $\mathrm{Ca}^{2+}$ activated $\mathrm{K}^{+}$channels activated by ATP in murine colonic smooth muscle. Am f Physiol 1997;273;C2010-21.

14 Vogalis F, Goyal RK. Activation of small conductance $\mathrm{Ca}(2+)$-dependent $\mathrm{K}+$ channels by purinergic agonists in smooth muscle cells of the mouse ileum. I Physiol 1997;502:497-508.

15 Sanders KM. A case for interstitial cells of Cajal as pacemakers and mediators of neurotransmission in the gastrointestinal tract. Gastroenterology 1996;111:492-515. 